\title{
Narrative verdicts and their impact on mortality statistics in England and Wales
}

Chris Hill and Lois Cook Office for National Statistics

\section{Abstract \\ Background}

Annually, there are around 30,000 coroner's inquests held in England and Wales that conclude with a verdict. 'Short form' verdicts such as accident or misadventure; natural causes; suicide; and homicide make up the majority of all verdict conclusions. 'Narrative' verdicts can be used by a coroner or jury, instead of a short form verdict, to express their conclusions as to the cause of death following an inquest. Since 2001 narrative verdicts have been more widely used, with over 3,000 narrative verdicts returned in 2009. In some cases, it can be difficult to code the underlying cause of death from the information provided in the narrative. For some time, the Office for National Statistics (ONS) and other organisations have been concerned about the impact of narrative verdicts on the quality of the statistics on cause of death. Our research investigated the impact of narrative verdicts on trends for deaths attributed to injury and poisoning in England and Wales.

\section{Methods}

The research considered narrative verdicts received by ONS between 2001 and 2009. All available information provided by the coroner from the narrative verdict, together with the underlying cause of death, was used in the analysis. All causes of death where a narrative verdict was returned were investigated. More in-depth analysis of accidental deaths was undertaken, as classification of these deaths by intent is more difficult when the information from the coroner is imprecise. A sensitivity analysis of suicide rates (intentional self-harm and event of undetermined intent) was carried out. This involved using two different scenarios of reclassifying selected proportions of accidental hanging and poisoning deaths, where a narrative verdict was returned, as intentional self-harm. An exercise to measure the consistency of coding cause of death from narrative verdicts was also undertaken. 


\section{Results}

The increasing proportion of narrative verdicts involving injury and poisoning has not significantly affected published mortality rates for suicide (intentional self-harm and injury or poisoning of undetermined intent). However, if the rise in narrative verdicts continues at the same rate, the accurate reporting of injury and poisoning deaths, including suicides, is likely to be affected. The exercise to establish the consistency of coding the cause of death by ONS cause coders showed that the current coding rules were being applied uniformly.

\section{Conclusions}

The increase in the use of narrative verdicts by coroners has not had a statistically significant impact on published suicide rates in England and Wales and so no revision to these rates is needed. A review of current coding practices and the handling of narrative verdicts will be undertaken by ONS with particular reference to deaths from intentional selfharm. A recommendation has been made to coroners to consider ways of recording narrative verdicts to allow more accurate coding of cause of death. This will ensure that mortality statistics are maintained to the highest standards. 


\section{Contents}

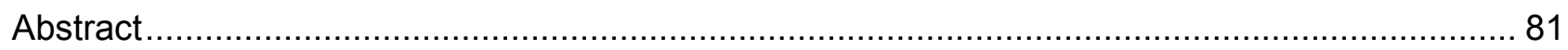

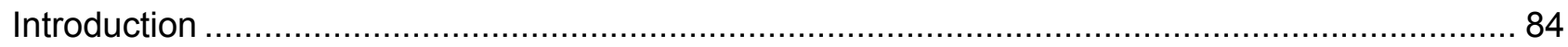

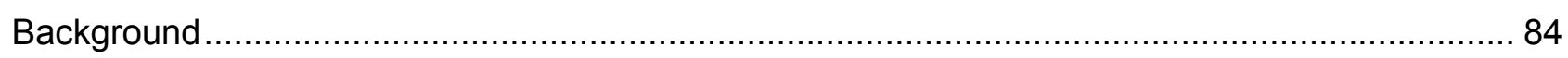

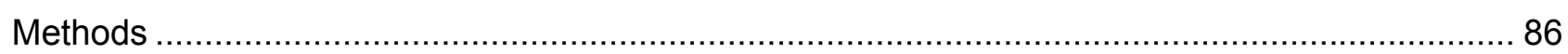

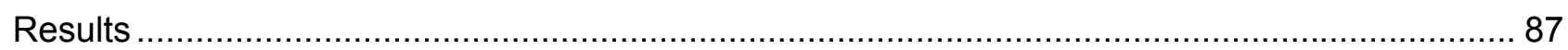

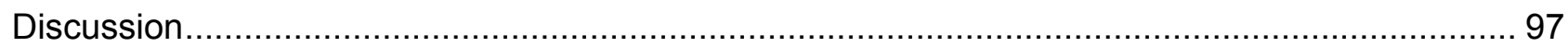

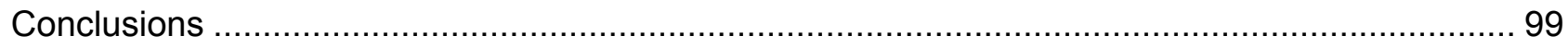

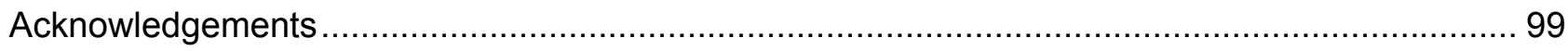

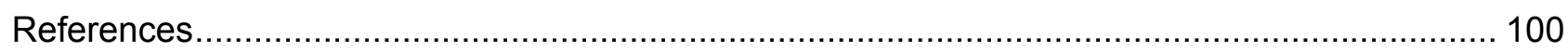

\section{List of Figures}

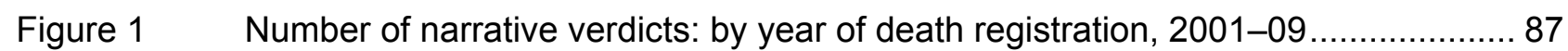

Figure $2 \quad$ Narrative verdicts by cause of death, 2001-09 ............................................... 88

Figure 3 Simulations of age-standardised mortality rates for suicide deaths, 2001-09 (scenario 1)

Figure 4 Simulations of age-standardised mortality rates for suicide deaths, 2001-09 (scenario 2)

\section{List of Tables}

Table $1 \quad$ Narrative verdicts classified as accidental deaths, 2001-09.

Table $2 \quad$ Narrative verdicts by selected mechanisms for all accidental deaths, 2001-09 .... 90

Table 3 Simulations of age-standardised mortality rates for suicide deaths: by sex, 2009

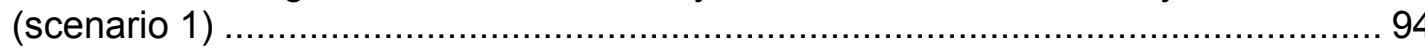

Table 4 Simulations of age-standardised mortality rates for suicide deaths: by sex, 2009

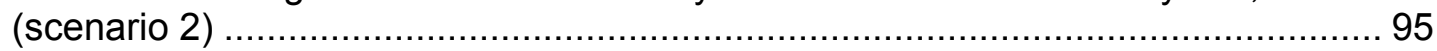

Table $5 \quad$ Changes in the ICD-10 broad cause of death group ........................................ 96 


\section{Introduction}

Mortality statistics provide a rich source of information for population health surveillance. They are used to assess the effectiveness of health and social care services and to evaluate the success of policies to reduce mortality rates. The reliability and accuracy of mortality statistics is crucial in the assessment of their impact. It is essential that the ONS is able to classify the cause of death accurately from information received from the certifier of the death.

Deaths can be divided into two main cause groups - those that are disease related, or have other internal conditions as their underlying cause of death; and those that are the result of an injury or poisoning and are attributed to an external cause of death. This distinction applies to all deaths, including those that have been the subject of an inquest. Where a narrative verdict is returned, the potential for misclassification of the injury and poisoning is greater if there is insufficient information from the certifier. If the narrative verdict does not contain sufficient detail about who caused the initial event leading to the death, or their intention at the time of the action, then the coder has to assign the death as an accident in accordance with international coding rules. This may affect the quality of mortality statistics.

\section{Background}

Coroners are independent judicial officers appointed and paid for by the relevant local authorities. They are responsible for investigating violent, unnatural deaths or sudden deaths of unknown cause that are reported to them, including all deaths occurring in custody. Coroners are also responsible for registering the cause of death for those deaths they investigate. Unnatural deaths exclude those deaths that have disease and other internal conditions as their underlying cause.

A coroner's inquest is an inquiry to establish the facts surrounding these types of death. The verdict following the inquest is usually returned in short-form format that fits into one of a series of established categories, for example, suicide, accident or misadventure. Alternatively, a narrative verdict can be returned by the coroner or jury. Narrative verdicts record the facts surrounding the death in more detail, but do not use a standard verdict to express their conclusions as to the cause of death. In some cases, it can be difficult to code the underlying cause of death from the information provided by the coroner in the narrative verdict. The aim of the research was to assess the impact of narrative verdicts on National Statistics relating to cause of death.

Since 2001 there has been a downward trend in the number of deaths registered in England and Wales. However, there has been an increase in the number of coroner's inquests over the same period. According to Ministry of Justice statistics (Ministry of Justice, 2010), the number of inquests opened in England and Wales has increased each year since 2001. In 2009 inquests were opened on around 31,000 deaths reported to coroners, compared with about 25,800 in 2001. 'Non-specific verdicts' (which include narrative verdicts) formed less than 1 per cent of all verdicts in 2001, but accounted for more than 13 per cent of verdicts in 2009. Recent case law may be responsible for the increased number of narrative verdicts in recent years, including the House of Lords 'Middleton' judgement (Ministry of Justice, 2010). The use of narrative verdicts by individual coroners varies throughout England and Wales. 


\section{Selecting the underlying cause of death}

The selection of the underlying cause of death is based on the Tenth Revision of the International Statistical Classification of Diseases and Related Health Problems, (ICD-10) (WHO, 1992-1994) and is derived from the condition or conditions reported by the certifier, as recorded on the medical certificate of cause of death. The underlying cause of death is defined by the World Health Organisation (WHO) as:

- the disease or injury that initiated the train of events directly leading to death, or

- the circumstances of the accident or violence that produced the fatal injury

In order to preserve the international comparability of statistics, and to take account of different medical and legal practices, internationally agreed rules have been devised to code the underlying cause of death from the information recorded on the death certificate and other supporting documentation.

While the majority of deaths in England and Wales have a cause of death assigned automatically by coding software, around 20 per cent $(100,000)$ of deaths are manually coded, including all deaths which have been the subject of an inquest.

When coding injury and poisoning deaths, both the intent and the mechanism determines how the death is assigned to an ICD code. The 'manner of death' (which equates to verdict in England and Wales) is also recorded. This includes accident, homicide, suicide, or event of undetermined intent if the intent could not be determined following investigation. The mechanism includes, for example, suffocation, drowning, poisoning or transport-related. As the majority of injury and poisoning deaths are investigated by a coroner, it is the verdict following the inquest, which should provide this information. Where a narrative verdict has been returned, details about the initial intent behind the act leading to the death, together with the mechanism used, may not always be clear from the facts provided by the coroner.

\section{Intentional self-harm}

To return a verdict of suicide, the coroner must be satisfied beyond reasonable doubt that the deceased intended to kill him/herself. However, in recognition of the different international medical and legal practices, the ICD code 'intentional self-harm' (which includes suicide), requires only that the certifier states that, to the best of their knowledge and belief, the initial event which led to the death was that the individual intended to harm himself/herself. As a high proportion of people who kill themselves are reported to be suffering from a mental health problem, (Harris and Barraclough, 1997; Pirkis and Burgess, 1998) it may be difficult to establish at an inquest whether the deceased was capable of understanding the consequences of their actions. In England and Wales it has been customary to assume that most injury and poisoning deaths, where the intent could not be determined following investigation, are those where the harm was self-inflicted, but there was insufficient evidence to prove that the deceased deliberately intended to kill themselves (Brock and Griffiths, 2003). Therefore, the definition of suicide used in ONS publications is any death given an underlying cause of intentional self-harm, or injury/poisoning of undetermined intent (Box 1). 


\section{Box 1 National Statistics definition of suicide \\ ICD-10 code \\ X60-X84 \\ $\mathrm{Y} 10-\mathrm{Y} 34^{1}$ \\ Description \\ Intentional self-harm \\ Injury/poisoning of undetermined intent}

1 From 2007 onwards, ONS has used ICD-10 code U50.9 for deaths with adjourned inquests. In the past, these deaths were coded to Y33.9. The principal reason for the change was to exclude these deaths from the Y10-Y34 range, making the tabulation of events of undetermined intent easier.

\section{Determining intent from narrative verdicts}

In some cases, the intent and mechanism are clearly stated in the narrative verdict. However, in a proportion of injury and poisoning deaths, where a narrative verdict has been returned, ONS has no indication from the information provided by the coroner of whether the fatal injury, or toxic substance, was self-administered, or if there was deliberate intent to self-harm. The rules of coding cause of death dictate that, where no indication of intent has been given by the certifier, deaths from injury or poisoning must be coded as accidents. Consequently, the net effect of the increase in narrative verdicts may have been to inflate the number of deaths classified as accidents and decrease the number classified as intentional self-harm. This is important, as trends in these types of death are closely monitored.

\section{Methods}

The analyses in this report focus on deaths with a narrative verdict received by ONS between 2001 and 2009 in England and Wales. Narrative verdicts were identified using the death registrations database. Variables selected for the analyses included age, sex, underlying cause of death and all coroner's text received by ONS. Descriptive statistics were produced and further analysis of the narrative text carried out to identify examples of text where the intent behind the initiating act causing the death was unclear.

\section{Sensitivity analysis}

To assess the potential impact of coroners providing insufficient detail in narrative verdicts to establish the intent, simulated age-standardised mortality rates (ASMRs) were calculated for each of the years 2001 to 2009 using two different assumptions. Firstly, mortality rates were calculated assuming all deaths, where a narrative verdict had caused the death to be coded as an accidental poisoning or hanging, were intentional self-harm (scenario 1). Secondly, rates were calculated assuming half of these deaths were intentional self-harm (scenario 2). Hangings and poisonings were used as these are the two most common methods for intentional self-harm in England and Wales. The ASMRs were calculated for all ages and were directly standardised using the European Standard Population. 


\section{Consistency of coding cause of death}

In order to assess the consistency of cause of death coding within ONS, an exercise was set up to evaluate any variation in the coding of narrative verdicts over time. All narrative verdicts, with the exception of neonatal deaths and transport accidents (V01-V99), were selected for the years 2004 to 2008. Neonatal deaths were excluded because they do not have an underlying cause of death. The reliability of coding transport accidents was assumed to be sufficiently high to allow the removal of these records. A total of 7,914 records were coded by eight experienced ONS cause coders who were able to see the coroner's text and cause of death text for each record, but not the original underlying cause of death code. Each case was coded and the results entered on a test database. A comparison could then be made between the original cause and the new cause, and any differences identified. A manner of death code, or verdict outcome, was also recorded by the coders in the exercise.

The coding frame used by ONS to classify the manner of death was also reviewed to ensure that it included common phrases used by coroners in their narrative verdicts.

\section{Results}

Since 2001 there has been a downward trend in the number of deaths registered in England and Wales, with the total number of registrations falling by around 8 per cent between 2001 and 2009 . Despite this trend, the number of coroner's inquests has been rising since 2001, together with the proportion of these with a narrative verdict.

\section{Figure 1 Number of narrative verdicts: by year of death registration, 2001-09}

England and Wales

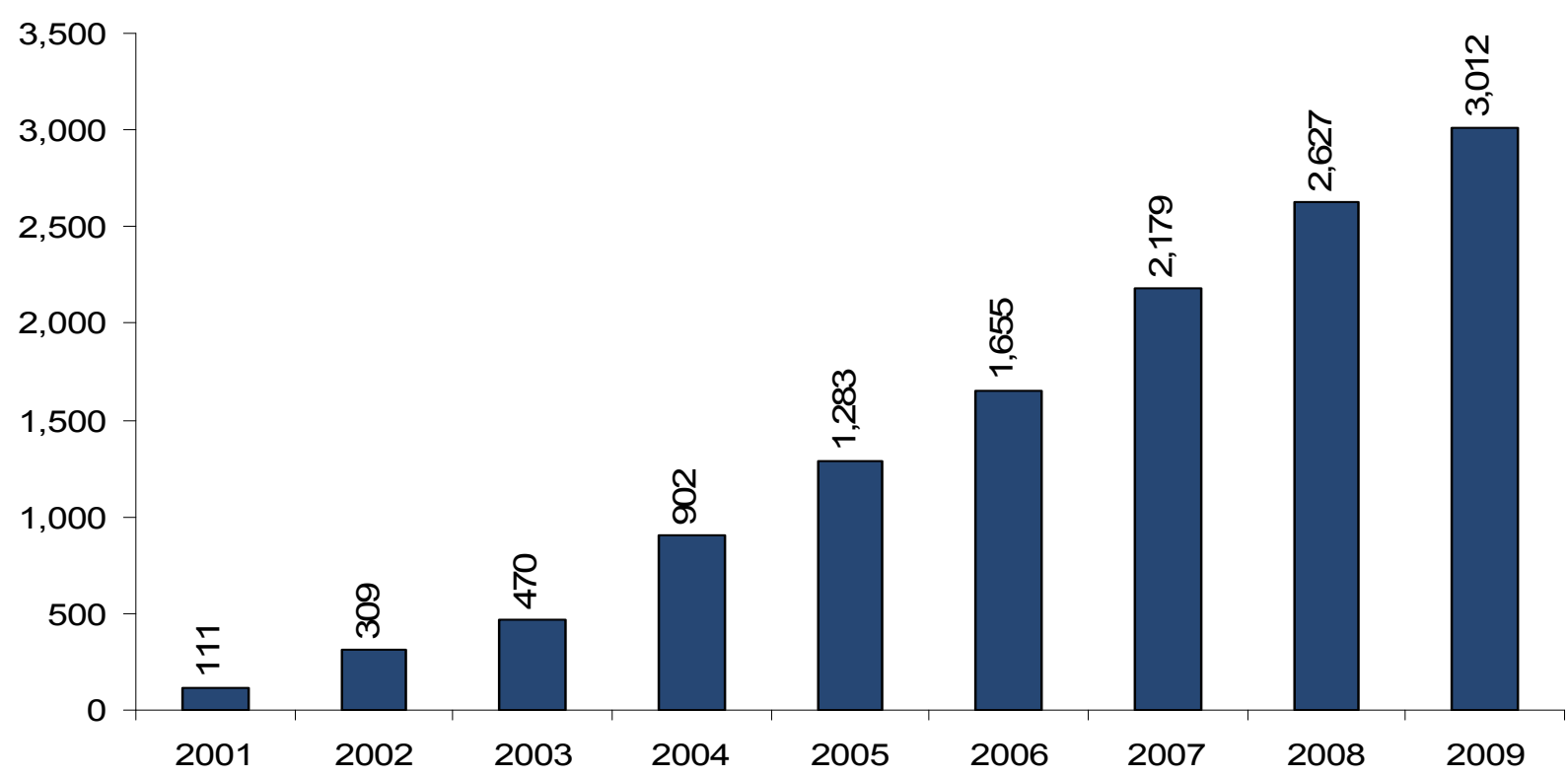

Source: ONS 
Between 2001 and 2009 there has been a 27-fold increase in narrative verdicts coded by ONS (Figure 1).

\section{Narrative verdicts and cause of death}

The increase in narrative verdicts has been associated with an increase in the proportion of these which are deaths from external causes, especially from 2005 onwards (Figure 2).

Figure 2 Narrative verdicts by cause of death, 2001-09

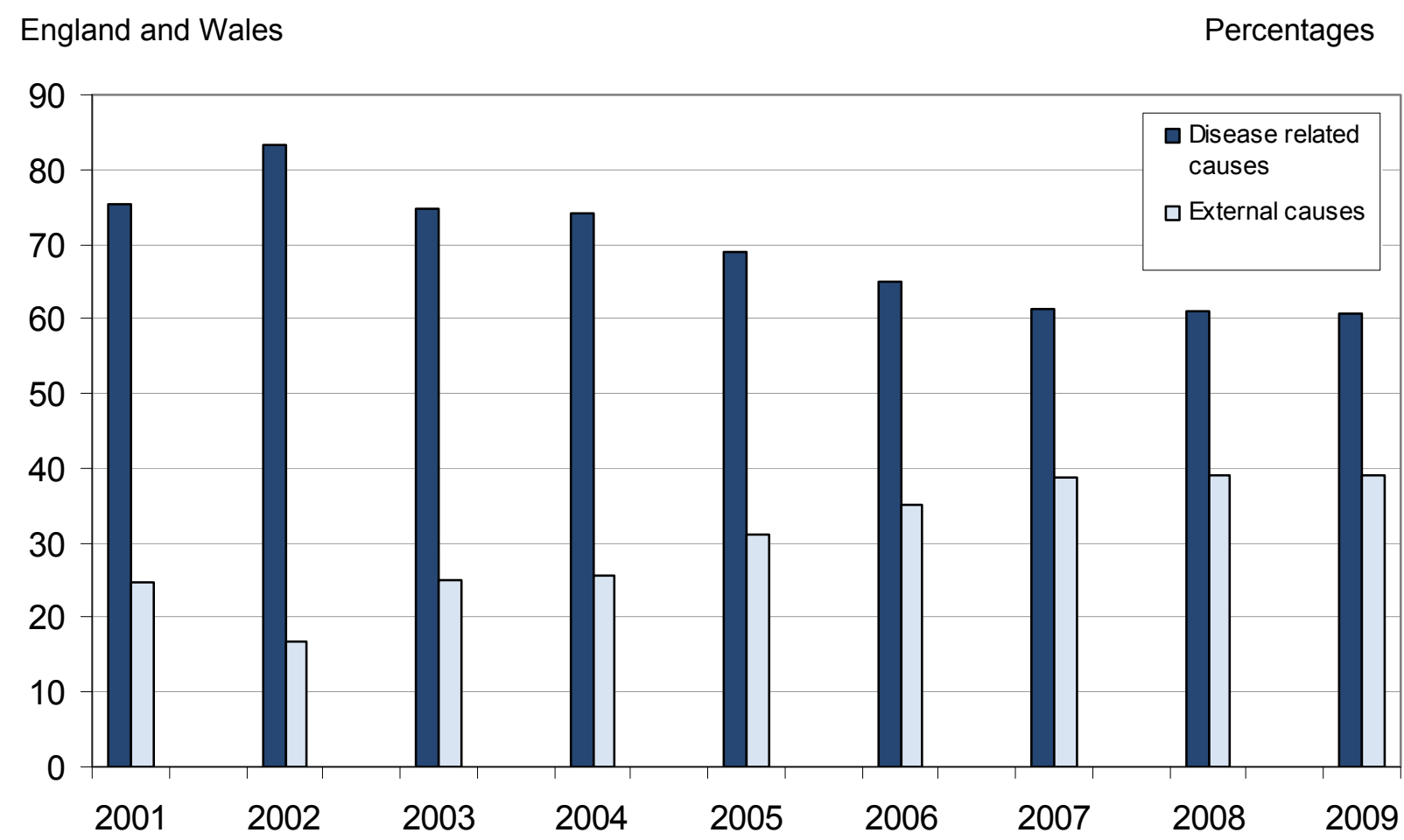

Source: ONS

Currently around 40 per cent of deaths with a narrative verdict are classified as having an external cause of death, compared with around 25 per cent in 2001. While the proportion of all deaths which are from external causes has remained stable over the period (around 3.5 per cent), there has been a slight increase in the proportion of these deaths classified as being accidental, from 2.1 per cent in 2001 to 2.4 per cent in 2009 (ONS, 2010). 


\section{Table $1 \quad$ Narrative verdicts classified as accidental deaths, 2001-09}

England and Wales

Number of verdicts, percentages

\begin{tabular}{|c|c|c|c|c|c|c|c|c|c|}
\hline & 2001 & 2002 & 2003 & 2004 & 2005 & 2006 & 2007 & 2008 & 2009 \\
\hline All narrative verdicts & 111 & 309 & 470 & 902 & 1,283 & 1,655 & 2,179 & 2,627 & 3,012 \\
\hline Narrative verdicts coded to accident & 21 & 25 & 58 & 155 & 295 & 457 & 728 & 908 & 1,002 \\
\hline \multicolumn{10}{|l|}{$\begin{array}{l}\text { Percentage of narrative verdicts where } \\
\text { the cause of death was accident }\end{array}$} \\
\hline & 18.9 & 8.1 & 12.3 & 17.2 & 23 & 27.6 & 33.4 & 34.6 & 33.3 \\
\hline
\end{tabular}

Source: ONS

Table 1 shows the increase in the proportion of narrative verdicts classified as having an accidental cause of death between 2001 and 2009. The proportion of narrative verdicts classified as being accidental deaths has risen from around a fifth (19 per cent) in 2001 to a third (33 per cent) in 2009. As mentioned above, unless there is sufficient information from the coroner to state otherwise, the coder has to classify the death as an accident in accordance with international coding rules.

\section{Types of accident}

Table 2 gives the aggregate numbers of accidental deaths for narrative verdicts by selected mechanism. Between 2001 and 2009 the two most common mechanisms for accidental deaths were transport accidents and falls, accounting for 50 per cent of the total. As these deaths are more likely to be accidental, the analyses concentrated on deaths from poisoning or suffocation (predominately hangings), these being the next two most common mechanisms. For these types of death, the intent behind the initial act leading to the death can be more difficult to determine from the information contained in a narrative verdict. It should also be noted that the majority of accidental deaths with an unspecified mechanism are likely to have been falls (Griffiths and Rooney, 2003).

In England and Wales the most common methods of suicide are hangings (including strangulation and suffocation) and poisonings. In 2009 these two mechanisms accounted for 60 per cent and 19 per cent of intentional self-harm deaths respectively (ONS, 2010). Where a narrative verdict had been returned, it is possible that a proportion of accidental deaths involving these two mechanisms could be classified as intentional self-harm, but there is insufficient detail in the narrative to confirm the intent. 


\section{Table $2 \quad$ Narrative verdicts by selected mechanisms for all accidental deaths, 2001-09}

England and Wales

\begin{tabular}{lrr}
\hline Mechanism & Number & Percentages \\
\hline Falls & 1,085 & 29.7 \\
Transport accidents & 745 & 20.4 \\
Poisoning & 679 & 18.6 \\
Suffocation & 408 & 11.2 \\
Drowning & 109 & 3.0 \\
Unspecified factor & 330 & 9.0 \\
Other accidents & 293 & 8.0 \\
All & 3,649 & $\mathbf{1 0 0 . 0}$ \\
\hline
\end{tabular}

Source: ONS

\section{Analysis of coroner's text}

Narrative verdicts vary in both length and detail ranging from a single line of text to detailed factual records, especially if the death occurred in custody. Some narrative verdicts contain all the information required to code accurately the underlying cause of death. In other cases, crucial detail is not provided.

The following examples illustrate deaths, where a narrative verdict has been returned, which are difficult to code. An example of the simplest narrative verdict record is where the cause of death is given as 'hanging', or 'suspension by ligature around neck' and the accompanying coroner's narrative verdicts reads 'On date at $x$, the deceased was found with a ligature around her neck.' The text does not provide any information as to whether there was a third party involved, nor if there was an intent to self-harm. With this vital detail missing, the cause of death code has to be accidental hanging as laid out in the ICD rules.

An example of a narrative verdict following a death in custody is ' $\mathrm{Mr} \mathrm{x}$, after being found hanging in his cell at $x$ youth offenders institution on date, died on date at $x$ infirmary. It was a serious omission by $x$ young offenders institute not to have informed $x$ 's parents on each occasion that $x$ had self-harmed. The jury's verdict is that $x$ died from hanging which caused his death.' With this example, there is some evidence that there was intent to self-harm because previous instances of this are mentioned in the narrative. However, as there is no mention of the intent surrounding the initiating act that caused the death, the death has to be classified as accidental.

There may also be references to use of drugs or alcohol, together with mentions of 'mental illness' which may cast doubt about whether the deceased was in control of their own actions. Again, without a clear mention of intent behind the hanging, these records must classified as accidental deaths. It should be noted that a proportion of hangings will be accidental, for example, a person 
playing a game, or an auto-erotic act that went too far. However, further analysis of over 400 records in this study involving hangings revealed that these events were rare.

For poisoning deaths, the information provided in the narrative verdict about the events surrounding the death can be less clear, especially where there is an overdose of drugs. A verdict of suicide will only be returned by the coroner if this is proved beyond reasonable doubt. For drug poisoning, there may not be any clear indication of intent to self-harm as the drugs may have been taken for recreational purposes. Similarly, there may not be sufficient detail in the narrative verdict regarding the involvement of any third party.

An example of a narrative verdict using the word 'overdose' is 'Died as a result of taking an overdose of heroin with alcohol'. The cause of death text on the coroner's form was 'Overdose of heroin with alcohol'. Again, there is no indication within the narrative verdict to verify if the overdose was self-administered and no indication of intent to self-harm. A similar example is 'Died following self-administration of an excessive amount of non-prescribed medication and alcohol'. Although this narrative text clearly states that the drug was self-administered there is doubt regarding the intent surrounding the taking of the non-prescribed medication with the alcohol. The intent may have been to 'get high' or to relieve pain, depending on the drug involved. A selfadministered overdose of heroin, codeine or co-proxamol, may tacitly point to accidental death, but this could still have been a deliberate act. As nothing can be assumed, the only option is to classify such deaths as accidental according to the ICD rules. Use of the word 'overdose' can be subjective when the quantities taken following the investigation are not mentioned in the narrative verdict.

Poisonings by other noxious substances were also reviewed. Accidental deaths from carbon monoxide poisoning were generally well documented with the narrative detailing a faulty gas boiler or blocked flue. However, where a person was found dead in a car from carbon monoxide poisoning, additional information to classify the cause of death could be absent with no indication of whether the deceased intended to kill her/himself.

\section{Sensitivity analysis - Hangings and poisonings}

The research investigated the impact of potential misclassification on trends in deaths attributed to intentional self-harm and events of undetermined intent. This is the National Statistics definition used by ONS to monitor trends in suicide deaths in England and Wales.

Figure 3 (scenario 1) shows the results of combining all accidental hangings and poisonings from narrative verdict records with existing suicide death rates (intentional self-harm deaths and event undetermined intent). This was carried out for hangings and poisonings both separately and jointly. Between 2001 and 2004, the inclusion of accidental hangings and poisonings had no effect on the suicide rate for England and Wales. In 2005 adding hangings increased the mortality rate from 84 deaths per million population, to 85 deaths per million population. A similar increase in the rate was seen in 2007. In 2008 the effect was greater, increasing the rate from 81 deaths per million population, to 83 deaths per million population, and likewise in 2009 the effect was to increase the rate from 82 deaths per million population to 84 deaths per million population. 
Between 2007 and 2009 a similar effect was seen when poisonings were included. In 2007 the rate increased from 76 deaths per million population to 79 deaths per million population. In 2008 the rate increased from 81 deaths per million population to 84 deaths per million population, and in 2009 , adding poisoning, increased the rate from 82 deaths per million population to 85 deaths per million population.

The effect of adding both accidental hangings and poisonings had greatest overall effect on the suicide mortality rates for 2008 and 2009.

\section{Figure $3 \quad$ Simulations ${ }^{1}$ of age-standardised mortality rates for suicide deaths $^{2}, 2001-09$ (scenario 1)}

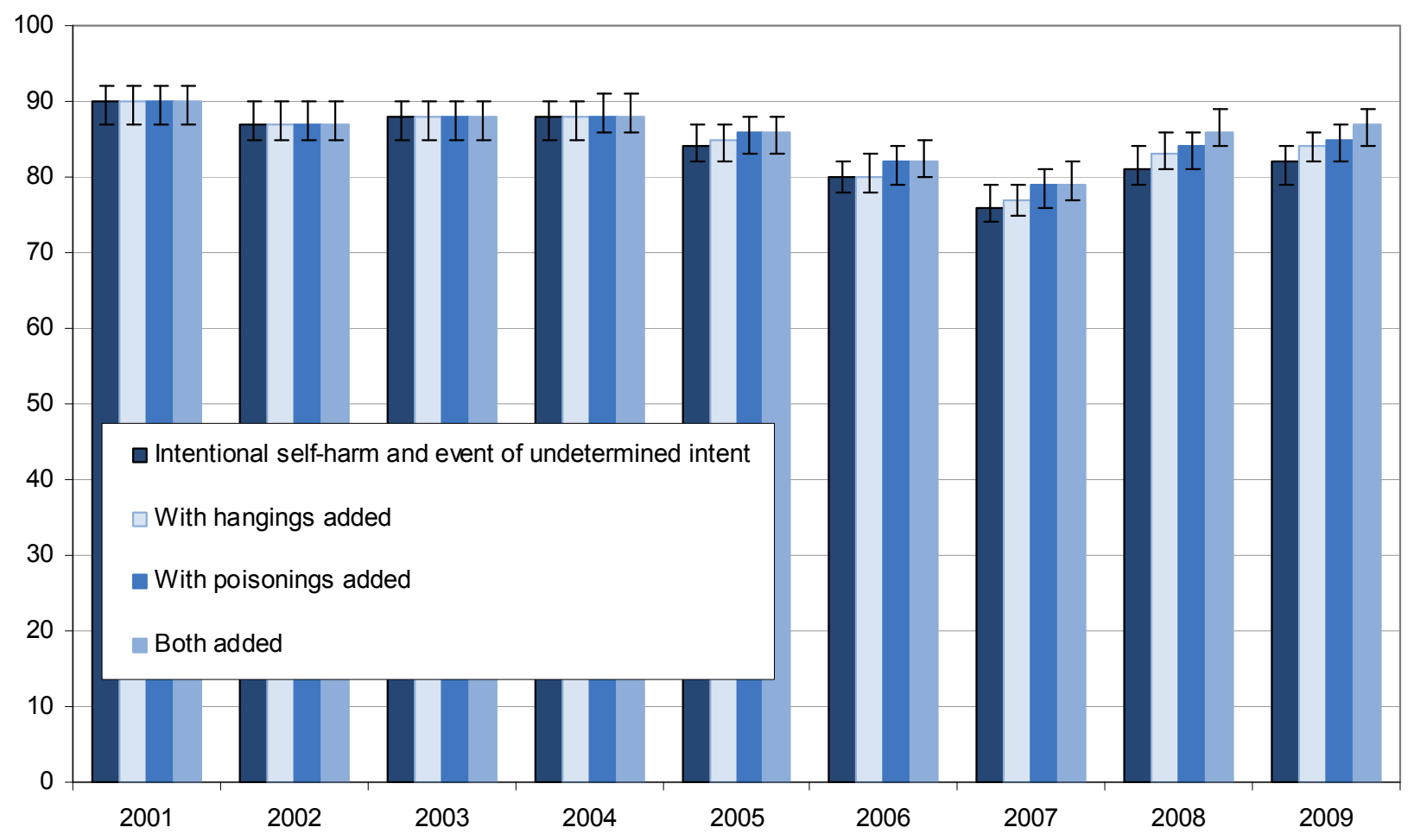

1 Addition of all deaths where the verdict was a narrative and the underlying cause of death was accidental hanging or poisoning.

2 Includes deaths with an underlying cause of death intentional self-harm and event of undetermined intent.

Source: ONS

In 2009 the effect of adding both accidental hangings and poisonings would increase the mortality rate from 82 deaths per million population, to 87 deaths per million population, the highest rate since 2004 when the suicide rate was 88 deaths per million population. The differences in the mortality rates are not statistically significant. This simulation could be considered the worst-case scenario as it assumes that all narrative verdicts coded as accidental hangings and poisonings should be classified as intentional self-harm. 
Figure 4 shows how the suicide rate would be change if half the accidental hanging and poisoning deaths with a narrative verdicts were added to those coded as intentional self-harm and events of undetermined intent (scenario 2). As in scenario 1, there is no effect on the rates between 2001 and 2004. For the remaining years the effect is less noticeable. In 2008 the effect of adding half of accidental hangings would increase the mortality rate from 81 deaths per million population, to 82 deaths per million population. In 2009 the effect was to increase the rate from 82 to 83 deaths per million population.

\section{Figure 4 Simulations ${ }^{1}$ of age-standardised mortality rates for suicide deaths ${ }^{2}, 2001-09$ (scenario 2)}

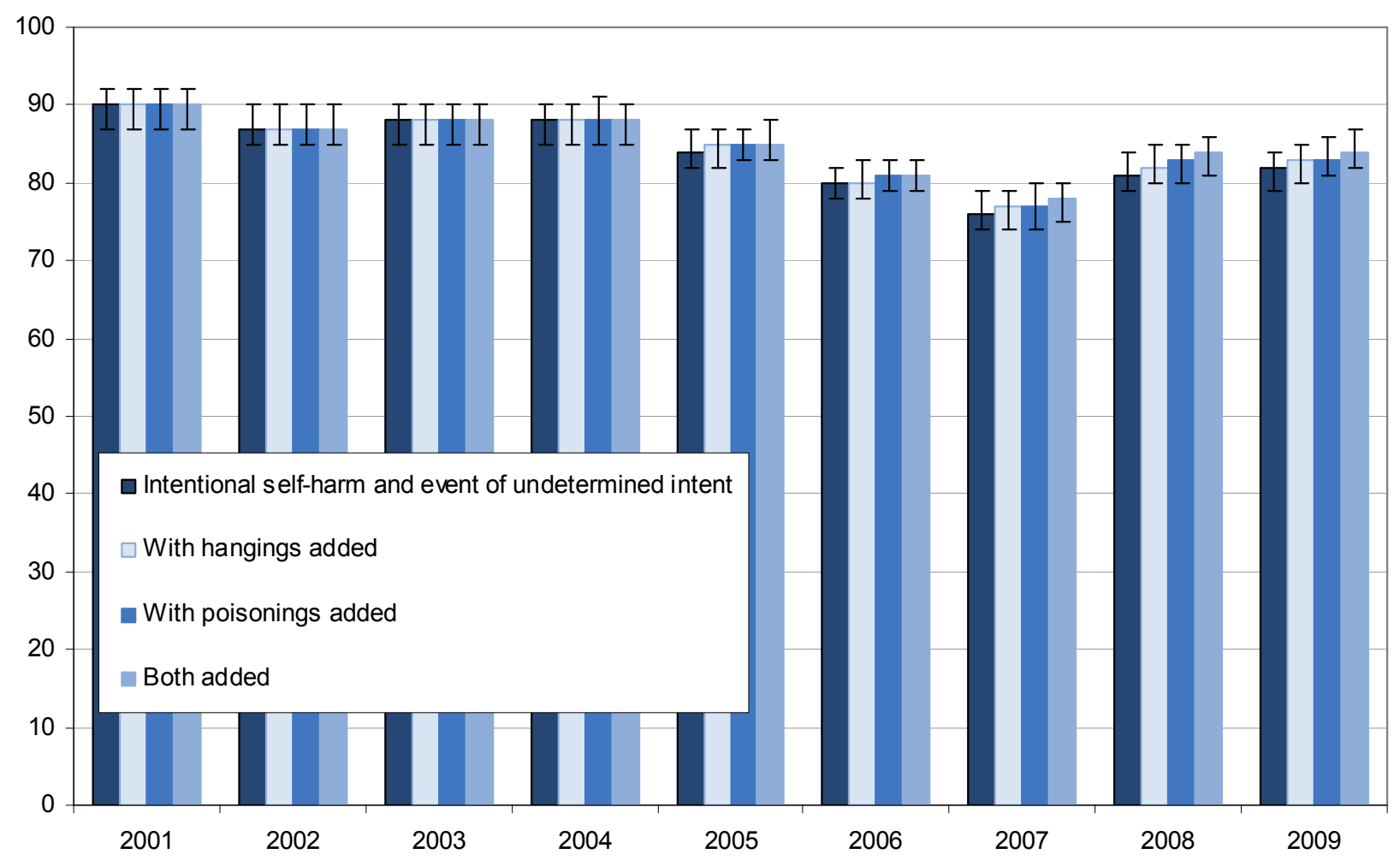

1 Addition of 50 per cent of deaths where the verdict was a narrative and the underlying cause of death was accidental hanging or poisoning.

2 Includes deaths with an underlying cause of death intentional self-harm and event of undetermined intent.

Source: ONS

Similar rises could be seen when half of accidental poisonings were included for years 2008 and 2009: with the mortality rate increasing to 83 deaths per million population, from 81 and 82 deaths per million population respectively for these years. Combining both hangings and poisonings with the intentional self-harm deaths would increase the mortality rate from 82 deaths per million population, to 84 deaths per million population in 2009. Again, the differences in the mortality rates are not statistically significant. While it is likely that a higher proportion of hangings than poisonings are intentional self-harm deaths, without sufficient information from the coroner, these deaths have to be classified as accidental. 
Gender specific rates were calculated for all years and the results were similar to the all persons figures shown in the simulations above. Tables 4 and 5 show the figures for the two simulations for males and females for 2009. For both scenarios, the effect for males is greater than for females. Table 3 shows the reported ASMRs together with the revised ASMRs once all accidental hangings and poisonings are added. For males the effect is most visible when both hangings and poisonings are included, increasing the rate from 127 deaths per million population to 134 deaths per million population. For females, the effect of combining these two mechanisms increased the rate from 38 deaths per million population to 41 deaths per million population.

\section{Table 3 Simulations of age-standardised mortality rates for suicide deaths: by sex, 2009 (scenario 1)}

England and Wales

Rate per million population

\begin{tabular}{|c|c|c|c|c|c|c|c|c|c|c|c|c|}
\hline \multirow[t]{2}{*}{2009} & \multicolumn{3}{|c|}{$\begin{array}{l}\text { Suicide (intentional self- } \\
\text { harm and event of } \\
\text { undetermined intent) }\end{array}$} & \multicolumn{3}{|c|}{$\begin{array}{l}\text { Addition of deaths where } \\
\text { the verdict was a narrative } \\
\text { and the underlying cause of } \\
\text { death was accidental } \\
\text { hanging }\end{array}$} & \multicolumn{3}{|c|}{$\begin{array}{l}\text { Addition of deaths where } \\
\text { the verdict was a narrative } \\
\text { and the underlying cause of } \\
\text { death was accidental } \\
\text { poisoning }\end{array}$} & \multicolumn{3}{|c|}{$\begin{array}{l}\text { Addition of deaths where } \\
\text { the verdict was a narrative } \\
\text { and the underlying cause of } \\
\text { death was accidental } \\
\text { hanging or poisoning }\end{array}$} \\
\hline & ASMR & $\begin{array}{l}\text { Lower } \\
95 \text { per } \\
\text { cent } \mathrm{Cl}\end{array}$ & $\begin{array}{l}\text { Upper } \\
95 \text { per } \\
\text { cent Cl }\end{array}$ & $\begin{array}{r}\text { New } \\
\text { ASMR }\end{array}$ & $\begin{array}{l}\text { Lower } \\
95 \text { per } \\
\text { cent } \mathrm{Cl}\end{array}$ & $\begin{array}{l}\text { Upper } \\
95 \text { per } \\
\text { cent Cl }\end{array}$ & $\begin{array}{r}\text { New } \\
\text { ASMR }\end{array}$ & $\begin{array}{l}\text { Lower } \\
95 \text { per } \\
\text { cent } \mathrm{Cl}\end{array}$ & $\begin{array}{l}\text { Upper } \\
95 \text { per } \\
\text { cent Cl }\end{array}$ & $\begin{array}{c}\text { New } \\
\text { ASMR }\end{array}$ & $\begin{array}{l}\text { Lower } \\
95 \text { per } \\
\text { cent Cl }\end{array}$ & $\begin{array}{l}\text { Upper } \\
95 \text { per } \\
\text { cent } \mathrm{Cl}\end{array}$ \\
\hline Males & 127 & (123) & (131) & 131 & (126) & (135) & 131 & (126) & (135) & 134 & $(130)$ & (139) \\
\hline Females & 38 & (35) & $(40)$ & 38 & $(36)$ & (41) & 40 & (37) & (42) & 41 & (38) & (43) \\
\hline
\end{tabular}

Source: ONS

Table 4 shows the effect of adding 50 per cent of accidental hangings and poisonings with a narrative verdict. Although the combination of both hangings and poisonings increases the rates by four deaths per million population for males from 127 to 131 deaths per million population, the differences in the rates are not statistically significant. The effect on the female rates was lower, and it is only the inclusion of the accidental poisonings that increases the rate from 38 deaths per million population, to 39 deaths per million population. 


\section{Table $4 \quad$ Simulations of age-standardised mortality rates for suicide deaths: by sex, 2009 (scenario 2)}

England and Wales

Rate per million population

\begin{tabular}{|c|c|c|c|c|c|c|c|c|c|c|c|c|}
\hline \multirow[t]{2}{*}{2009} & \multicolumn{3}{|c|}{$\begin{array}{l}\text { Suicide (intentional self- } \\
\text { harm and event of } \\
\text { undetermined intent) }\end{array}$} & \multicolumn{3}{|c|}{$\begin{array}{l}\text { Addition of } 50 \text { per cent } \\
\text { deaths where the verdict } \\
\text { was a narrative and the } \\
\text { underlying cause of death } \\
\text { was accidental hanging }\end{array}$} & \multicolumn{3}{|c|}{$\begin{array}{l}\text { Addition of } 50 \text { per cent of } \\
\text { deaths where the verdict } \\
\text { was a narrative and the } \\
\text { underlying cause of death } \\
\text { was accidental poisoning }\end{array}$} & \multicolumn{3}{|c|}{$\begin{array}{c}\text { Addition of } 50 \text { per cent of } \\
\text { deaths where the verdict } \\
\text { was a narrative and the } \\
\text { underlying cause of death } \\
\text { was accidental hanging or } \\
\text { poisoning }\end{array}$} \\
\hline & ASMR & $\begin{array}{l}\text { Lower } \\
95 \text { per } \\
\text { cent } \mathrm{Cl}\end{array}$ & $\begin{array}{l}\text { Upper } \\
95 \text { per } \\
\text { cent Cl }\end{array}$ & $\begin{array}{r}\text { New } \\
\text { ASMR }\end{array}$ & $\begin{array}{l}\text { Lower } \\
95 \text { per } \\
\text { cent Cl }\end{array}$ & $\begin{array}{l}\text { Upper } \\
95 \text { per } \\
\text { cent Cl }\end{array}$ & $\begin{array}{r}\text { New } \\
\text { ASMR }\end{array}$ & $\begin{array}{l}\text { Lower } \\
95 \text { per } \\
\text { cent } \mathrm{Cl}\end{array}$ & $\begin{array}{l}\text { Upper } \\
95 \text { per } \\
\text { cent Cl }\end{array}$ & $\begin{array}{c}\text { New } \\
\text { ASMR }\end{array}$ & $\begin{array}{l}\text { Lower } \\
95 \text { per } \\
\text { cent } \mathrm{Cl}\end{array}$ & $\begin{array}{l}\text { Upper } \\
95 \text { per } \\
\text { cent Cl }\end{array}$ \\
\hline Males & 127 & (123) & (131) & 129 & (124) & (133) & 129 & (124) & (133) & 131 & (126) & (135) \\
\hline Females & 38 & (35) & (40) & 38 & (36) & (40) & 39 & (36) & (41) & 39 & (37) & (41) \\
\hline
\end{tabular}

Source: ONS

\section{Consistency of cause coding for narrative verdicts}

The results of the cause coding exercise are shown in Table 5. Analysis of the new cause codes against the existing codes showed that 22 per cent of records $(1,731)$ were not an exact match at the fourth digit level of the ICD-10 cause code and 10 per cent of records (797) had moved to another cause. Of the 797 records that had moved cause grouping, nearly a third (31 per cent) were now classified as external causes of mortality. A further 18 per cent had moved to diseases of the circulatory system and 9 per cent to both diseases of the digestive system and diseases of the respiratory system. The remainder were spread across other causes.

Although 247 records were reclassified as external causes of death, 211 records originally coded as external causes moved to other cause groups with the majority of these (46 per cent) classified as diseases of the circulatory system or the respiratory system. There were 10 per cent now classified as mental and behavioural disorders and a similar proportion ( 9 per cent) as diseases of the digestive system. Although the movement in and out of the external cause group experienced the greatest change, overall there was only a net gain of 36 records for external causes.

There were only five new records with an underlying cause of intentional self-harm. These records had originally been classified as accidental, demonstrating a high consistency of coding these potentially difficult to code records. For accidental hangings and poisonings, there were match rates of 93 and 92 per cent respectively.

The research showed that although in some the cases the coders assigned a different underlying cause of death, overall they applied the ICD classification rules consistently.

The examination of the manner of death coding frame showed that additional terms commonly used by coroners to describe intentional-self harm could be included to improve the accuracy of coding some narrative verdicts. Improvements could also be made to identify more easily that the manner of death had been obtained from a narrative verdict. 


\section{Table 5 Changes in the ICD-10 broad cause of death group}

\begin{tabular}{|c|c|c|c|c|c|c|c|c|c|c|c|c|c|c|c|c|c|c|c|}
\hline \multirow{2}{*}{$\begin{array}{l}\text { Broad cause of death group } \\
\text { (ICD-10 capters) } \\
\text { Existing cause of death code }\end{array}$} & \multicolumn{18}{|c|}{ New cause of death code } & \\
\hline & 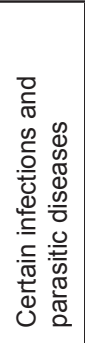 & $\begin{array}{l}\frac{0}{2} \\
0 \\
\frac{\pi}{0} \\
\frac{0}{0} \\
z \\
\frac{\Phi}{2}\end{array}$ & 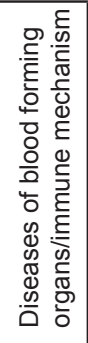 & 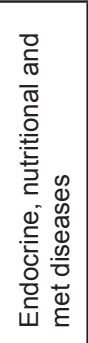 & 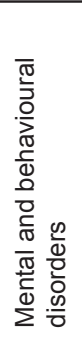 & 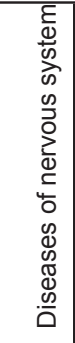 & 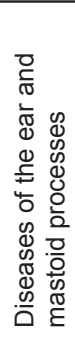 & 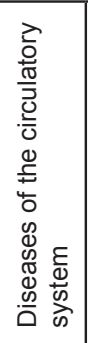 & 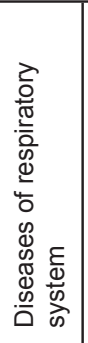 & 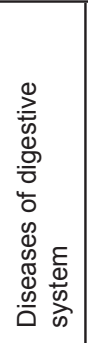 & 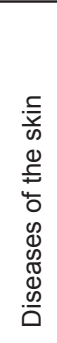 & 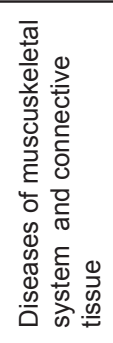 & 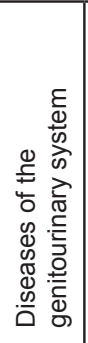 & 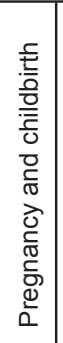 & 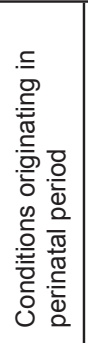 & 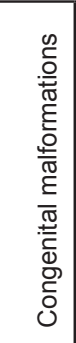 & 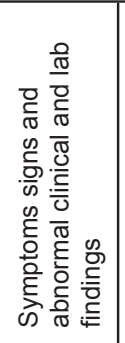 & 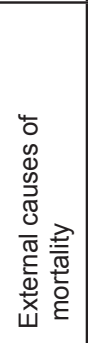 & 愛 \\
\hline $\begin{array}{l}\text { Certain infections and parasitic } \\
\text { diseases }\end{array}$ & 99 & 3 & 1 & 2 & 0 & 1 & 0 & 2 & 3 & 1 & 0 & 0 & 2 & 0 & 1 & 0 & 0 & 8 & 123 \\
\hline Neoplasms & 1 & 1260 & 1 & 0 & 0 & 1 & 0 & 8 & 2 & 12 & 0 & 0 & 1 & 0 & 0 & 0 & 0 & 12 & 1298 \\
\hline $\begin{array}{l}\text { Diseases of blood forming } \\
\text { organs/immune mechanism }\end{array}$ & 0 & 2 & 20 & 0 & 0 & 0 & 0 & 0 & 0 & 1 & 1 & 0 & 0 & 0 & 0 & 0 & 0 & 3 & 27 \\
\hline $\begin{array}{l}\text { Endocrine, nutritional and met } \\
\text { diseases }\end{array}$ & 1 & 2 & 0 & 112 & 3 & 0 & 0 & 3 & 0 & 2 & 0 & 3 & 1 & 0 & 1 & 0 & 0 & 5 & 133 \\
\hline Mental and behavioural disorders & 1 & 0 & 1 & 1 & 102 & 1 & 0 & 7 & 3 & 2 & 1 & 0 & 1 & 1 & 0 & 0 & 2 & 14 & 137 \\
\hline Diseases of nervous system & 0 & 0 & 0 & 1 & 4 & 105 & 0 & 3 & 0 & 0 & 0 & 2 & 0 & 1 & 0 & 0 & 0 & 7 & 123 \\
\hline $\begin{array}{l}\text { Diseases of the ear and mastoid } \\
\text { processes }\end{array}$ & 0 & 0 & 0 & 0 & 0 & 0 & 2 & 0 & 0 & 0 & 0 & 0 & 0 & 0 & 0 & 0 & 0 & 0 & 2 \\
\hline Diseases of the circulatory system & 3 & 3 & 1 & 6 & 4 & 0 & 0 & 1316 & 7 & 17 & 1 & 8 & 6 & 0 & 0 & 4 & 1 & 77 & 1454 \\
\hline Diseases of respiratory system & 4 & 5 & 1 & 0 & 2 & 2 & 0 & 12 & 238 & 2 & 1 & 1 & 0 & 0 & 1 & 2 & 1 & 12 & 284 \\
\hline Diseases of digestive system & 9 & 7 & 0 & 3 & 2 & 1 & 0 & 26 & 9 & 760 & 0 & 6 & 2 & 0 & 2 & 1 & 2 & 65 & 895 \\
\hline Diseases of the skin & 2 & 0 & 0 & 1 & 0 & 0 & 0 & 3 & 0 & 0 & 23 & 0 & 1 & 0 & 0 & 0 & 0 & 3 & 33 \\
\hline $\begin{array}{l}\text { Diseases of musculoskeletal system } \\
\text { and connective tissue }\end{array}$ & 2 & 0 & 0 & 0 & 0 & 4 & 0 & 8 & 6 & 10 & 1 & 345 & 1 & 0 & 0 & 1 & 0 & 18 & 396 \\
\hline Diseases of the genitourinary system & 1 & 2 & 1 & 3 & 1 & 1 & 0 & 5 & 1 & 5 & 0 & 1 & 146 & 0 & 0 & 1 & 0 & 16 & 184 \\
\hline Pregnancy and childbirth & 0 & 0 & 0 & 0 & 0 & 0 & 0 & 0 & 0 & 0 & 0 & 0 & 1 & 25 & v & 0 & 0 & 0 & 26 \\
\hline $\begin{array}{l}\text { Conditions originating in perinatal } \\
\text { period }\end{array}$ & 0 & 0 & 0 & 0 & 0 & 0 & 0 & 1 & 0 & 0 & 0 & 0 & 0 & 0 & 11 & 0 & 0 & 2 & 14 \\
\hline Congenital malformations & 0 & 0 & 0 & 0 & 0 & 2 & 0 & 4 & 2 & 2 & 0 & 0 & 3 & 0 & 0 & 111 & 1 & 2 & 127 \\
\hline $\begin{array}{l}\text { Symptoms signs and abnormal } \\
\text { clinical and lab findings }\end{array}$ & 0 & 0 & 0 & 0 & 0 & 1 & 0 & 1 & 0 & 0 & 0 & 0 & 0 & 0 & 0 & 0 & 192 & 3 & 197 \\
\hline External causes of mortality & 7 & 9 & 3 & 6 & 22 & 11 & 1 & 63 & 35 & 20 & 2 & 10 & 10 & 0 & 0 & 2 & 10 & 2250 & 2461 \\
\hline ta & 130 & 1293 & 29 & 135 & 140 & 130 & 3 & 1462 & 306 & 834 & 30 & 376 & 175 & 27 & 16 & 122 & 209 & 2497 & 7914 \\
\hline
\end{tabular}

Source: ONS 


\section{Discussion}

There has been a sharp increase in the number of narrative verdicts returned by coroners in England and Wales since 2001. If there is insufficient information received from the coroner, the death has to be coded as accidental. The results of the exercise on coding consistency compare well with other studies of cause of death coding reliability (Harteloh et al., 2010). However, it is apparent that some difficult to code injury and poisoning records are being coded as accidents when they may be intentional self-harm deaths.

The simulation of higher suicide mortality rates by adding half or even all accidental deaths involving hangings and poisonings to intentional self-harm deaths did not significantly affect the reported mortality rates for 2001 to 2009 . However, if the current trend in the use of narrative verdicts continues, and the proportion of these that are difficult to code also increases, this is likely to affect significantly reported mortality rates in the future.

Cause of death coders are reliant solely on the description of the events surrounding the death contained in the narrative text, together with the cause of death, to classify the death according to ICD rules. The ICD rules do not allow the coder to infer anything, and without clear reporting by the coroner of the intent, or involvement of a third party, the death has to be coded as an accident. However as the use of narrative verdicts is increasing, action is required to ensure that the results of coroners' investigation of deaths are used to provide the best possible information to code the underlying cause of death.

It is clear that trying to establish intent, or the involvement of third party, is difficult if there is limited information from the coroner. Form Rev $99 \mathrm{~B}$ (Part V) is used by coroners to provide information for statistical purposes to allow the cause of death to be coded according to ICD rules. However, at present the coroner is only asked to provide further information if the death is an accident or misadventure, although many coroners complete this section for all deaths that they register. As all the information provided on the Part $V$ is used to code cause of death, it would be logical to add tick boxes to this form to establish the manner of death. The categories for manner of death would be:

- natural disease

- accidental injury and poisoning

- intentional self-harm

- assault

- event undetermined intent

- legal intervention

- operation of war

- complication of medical or surgical care

ONS is currently working with coroners to consider ways of recording information from narrative verdicts to allow more accurate coding of cause of death. 
Limitations were also found in the coding frame used to code the manner of death. Additional common phrases used by coroners in their narrative verdicts were identified and additions to the terms allowed for classification of intentional self-harm will be added to the existing coding frame. Improvements will also allow better identification that the death was registered with a narrative verdict. Analysis of the impact of these changes on mortality statistics is planned for 2011.

\section{Limitations of the analysis}

The research focused on the two dominant methods for intentional self-harm - hanging and poisoning. Narrative verdicts classified as accidental deaths involving these two mechanisms were investigated and revised mortality rates calculated using simulations. Other mechanisms for intentional self-harm, for example drowning, were not considered in the analysis as the numbers of deaths using these methods were found to be relatively small. However, a combination of all possible mechanisms may affect the sensitivity analysis although this was not investigated.

The cause coding exercise only used selected narrative verdict records for 2004 to 2008 . This was due to the time involved in carrying out such an exercise and the fact that processed records for 2009 were not available for use at the time the coding exercise was carried out. Some of the records may have been recoded by the coder who originally coded the death. This could have had an effect on the results, as a proportion of records may have been familiar to the coder involved. However, it was not possible to measure the level of overlap from the data supplied.

Although all available text received from coroners was reviewed, sometimes the narrative verdict was missing from the record provided at death registration. For a small proportion of deaths, this information cannot be obtained even after requests from the relevant coroner. If the information simply mentions that there was a narrative verdict, then the coder has to classify the death as accidental according to ICD rules.

In order to establish any regional variation in the use of narrative verdicts, further research by coroner district will be needed. If a high percentage of narrative verdicts are used by a small number of coroners this could have an effect on mortality rates at local area level, especially if the level of detail from these coroners does not allow for accurate coding of the intent. The effectiveness of measures to reduce intentional self-harm at local area level could therefore be misleading, if trends are based on statistics that over report accidental deaths. Further research by geography is planned for the future. 


\section{Conclusions}

This article reviews the impact of narrative verdicts on mortality statistics in England and Wales from 2001 to 2009. The findings show that, while the coding of narrative verdicts has been consistent over the period, the lack of clear information from some coroners, relating to the intent, or involvement of a third party, can affect the coding of the underlying cause of death. This means that some deaths may have been classified as accidental, when they are more likely to be intentional, but the effect on reported suicide mortality rates is not statistically significant. Consequently, there will not be a revision of previously published mortality rates for these years. However, if current trends in the use of narrative verdicts continue, the effect on mortality rates may become large enough to affect the reliability of National Statistics. To help overcome this, some improvements have been made to the coding frame used by ONS to record the manner of death following an inquest. ONS is also working with coroners to consider ways of recording information from narrative verdicts to allow more accurate coding of cause of death.

\section{Acknowledgements}

The authors would like to thank Dr. Cleo Rooney and all of the ONS cause coding team for their help with this research. 


\section{References}

Brock A and Griffiths C (2003) 'Trends in suicide by method in England and Wales, 1979-2001', Health Statistics Quarterly 20, pp 7-18, available at:

www.statistics.gov.uk/downloads/theme health/HSQ20.pdf

Griffiths C and Rooney C (2003) 'The effect of the introduction of ICD-10 on trends in mortality from injury and poisoning in England and Wales, 1999', Health Statistics Quarterly 14, pp 75-83, available at: www.statistics.gov.uk/downloads/theme health/HSQ14 v4.pdf

Harris E C, Barraclough, B (1997), 'Suicide as an outcome for mental disorders', British Journal of Psychiatry 170, pp 205-228.

Harteloh P, de Bruin K, Kardman J (2010) 'The reliability of cause-of-death coding in The Netherlands', European Journal of Epidemiology 25 (8), pp 531-538.

Ministry of Justice (2010), Statistics on deaths reported to coroners England and Wales, 2009, available at: www.justice.gov.uk/publications/coronersannual.htm

Office for National Statistics (2010) Mortality statistics: Deaths registered in 2009, available at: www.statistics.gov.uk/statbase/product.asp?vlnk=15096

Pirkis J, Burgess P. (1998) 'Suicide and recency of health care contacts. A systematic review', British Journal of Psychiatry 173, pp 462-474.

World Health Organisation (WHO) (1992-94) International Statistical Classification of Diseases and Related Health Problems, volumes 1, 2 and 3 (Tenth Revision). WHO: Geneva. 